\title{
When a vaccine is safe
}

\section{Unfounded public fears place pressures on vaccine developers that go beyond reasonable safety considerations, as the search for an acceptable vaccine against Lyme disease may demonstrate.}

$\mathrm{N}$ othing gets forgotten as quickly as the threat of an epidemic that has been successfully headed off. Just look at all the allegations of media hype over SARS (severe acute respiratory syndrome), by people who think it was not a threat because so few ended up contracting it.

The short public memory reflects a low level of awareness of the largely invisible public-health activities that can now prevent infectious diseases running unchecked through human populations like they used to do - and as SARS might have done without the stringent quarantines and travel bans imposed to contain it. In wealthy countries, a lack of personal experience of infectious diseases has also induced a lack of respect for two of the main weapons that keep them at bay - antibiotics and vaccines.

Inappropriate use of antibiotics has allowed microbes to become resistant to many common treatments, creating serious health-care problems. And public suspicion of vaccines can undermine programmes aimed at eradicating particular diseases: the hostility in Britain to the measles, mumps and rubella (MMR) vaccine, based on unfounded fears that it might cause autism, is a case in point (see Nature 439, 1-2; 2006).

Vaccination programmes often face problems of public acceptance as, by definition, they treat large numbers of healthy people. It is easier to provide a convincing case for vaccination when the risk of catching a disease is high and the consequences of infection severe. But what about a disease such as Lyme disease, where the risk of infection is relatively small, and the consequences not so deadly?

Lyme disease is transmitted by deer ticks, and is not transmitted person-to-person. The risk of infection is limited to areas where people share territory with deer, including swathes of central Europe and a growing envelope of rural and suburban North America. The disease is nasty but does not normally kill, and it can usually be cured by antibiotics. Confidence in the first Lyme disease vaccine stumbled after 1999, when it became available in the United States. A campaign claiming that the vaccine caused side effects, including autoimmunity (see News Feature, page 524), caused sales to plummet, and the manufacturer GlaxoSmithKline withdrew the vaccine in 2002.

So what does a vaccine maker have to gain from trying again? Baxter Vaccines, based in Vienna, Austria, must be asking itself this question. It has invested sizeable resources in developing a new vaccine, and is considering whether to put it into cinical trials. Baxter is not the only company seeking a Lyme vaccine, so manufacturers are clearly convinced that a potential market exists.

One reason for that is the growing extent of the disease, especially in the sprawling suburbs of the United States, where the number of cases in areas with systematic surveillance has doubled since the early 1990s. Good statistics are not available for Europe, but one study in eastern Germany showed the incidence up by one-
"Those who live in areas where Lyme disease is spreading deserve a vaccine." third between 2002 and 2003. In Austria, the disease is endemic, with 130 new cases each year per 100,000 people.

Baxter will be hoping that increasing risk to the public will reduce the aversion to a vaccine. US physicians note that those keenest to be vaccinated tend to have first-hand experience of the disease and its unpleasant treatment, which involves weeks of injections with powerful antibiotics. Baxter's candidate vaccine has been engineered to remove the part of a protein that the opponents to the vaccine held responsible for causing problems, even though the US Food and Drug Administration found no evidence for such harm.

It may go against the scientific grain for marketing considerations to play such a part in steering vaccine development. But in the real world, this may be unavoidable. Lyme disease is a serious illness and those who live in areas where it is spreading deserve a vaccine.

ultimately set back any prospect of reviving the former.

When it is released next week, Bush's 2007 budget proposal is expected to include a provision that would start to revive nuclearfuel reprocessing. That would end a three-decade-old strategy in the United States that has sought to sever the connection between nuclear power and nuclear weapons.

Nuclear-fuel reprocessing aims to reduce the volume of spent nuclear fuel that has to be disposed of safely by recycling it for use in new types of nuclear reactor. But the recycling involves separating components that can readily be used to build nuclear weapons.

Of the countries with significant nudear power capacity, the United States and Germany abandoned reprocessing early on, and Britain, having ditched the fast-reactor design that would burn the recycled fuel, looks set to follow suit. Japan is trying to build a between nuclear energy and nuclear weapons - and could 